\title{
Factors Associated with Enrolment of Households in Nepal's National Health Insurance Program
}

\author{
Prabesh Ghimire ${ }^{* \mathbb{Q}}$, Vishnu Prasad Sapkota, Amod Kumar Poudyal
}

\begin{abstract}
Background: Nepal has made remarkable efforts towards social health protection over the past several years. In 2016, the Government of Nepal introduced a National Health Insurance Program (NHIP) with an aim to ensure equitable and universal access to healthcare by all Nepalese citizens. Following the first year of operation, the scheme has covered 5 percent of its target population. There are wider concerns regarding the capacity of NHIP to achieve adequate population coverage and remain viable. In this context, this study aimed to identify the factors associated with enrolment of households in the NHIP.

Methods: A cross-sectional household survey using face to face interview was carried out in 2 Palikas (municipalities) of Ilam district. 570 households were studied by recruiting equal number of NHIP enrolled and non-enrolled households. We used Pearson's chi-square test and binary logistic regression to identify the factors associated with household's enrolment in NHIP. All statistical analyses were performed using IBM SPSS version 23 software.

Results: Enrolment of households in NHIP was found to be associated with ethnicity, socio-economic status, past experience of acute illness in family and presence of chronic illness. The households that belonged to higher socioeconomic status were about 4 times more likely to enrol in the scheme. It was also observed that households from privileged ethnic groups such as Brahmin, Chhetri, Gurung, and Newar were 1.7 times more likely to enrol in NHIP compared to those from underprivileged ethnic groups such as janajatis (indigenous people) and dalits (the oppressed). The households with illness experience in 3 months preceding the survey were about 1.5 times more likely to enrol in NHIP compared to households that did not have such experience. Similarly, households in which at least one of the members was chronically ill were 1.8 times more likely to enrol compared to households with no chronic illness. Conclusion: Belonging to the privileged ethnic group, having a higher socio-economic status, experiencing an acute illness and presence of chronically ill member in the family are the factors associated with enrolment of households in NHIP. This study revealed gaps in enrolment between rich-poor households and privileged-underprivileged ethnic groups. Extension of health insurance coverage to poor and marginalized households is therefore needed to increase equity and accelerate the pace towards achieving universal health coverage.

Keywords: National Health Insurance Program, Health Insurance Board, Enrolment, Nepal

Copyright: @ 2019 The Author(s); Published by Kerman University of Medical Sciences. This is an open-access article distributed under the terms of the Creative Commons Attribution License (http://creativecommons.org/licenses/ by/4.0), which permits unrestricted use, distribution, and reproduction in any medium, provided the original work is properly cited.

Citation: Ghimire P, Sapkota VP, Poudyal AK. Factors associated with enrolment of households in Nepal's national health insurance program. Int J Health Policy Manag. 2019;8(11):636-645. doi:10.15171/ijhpm.2019.54
\end{abstract}

Article History:

Received: 23 September 2018

Accepted: 23 June 2019

ePublished: 7 July 2019

\section{*Correspondence to:}

Prabesh Ghimire

Email:

prabeshghimire@outlook.com

\section{Key Messages}

Implications for policy makers

A National Health Insurance Program (NHIP) was designed to ensure equitable access to healthcare by all Nepalese citizens. This paper raises questions about how to ensure equitable participation of poor and ethnically disadvantaged families into the risk pool of NHIP.

- In this study, households with poor socio-economic status enrolled less as compared to richer families. Health insurance board and government must create robust measures to timely identify and subsidize poorer households as stipulated in the national health insurance policy.

- Results also show that enrolment in NHIP is disproportionally concentrated among the privileged ethnic groups. Hence, Health Insurance Board and policy-makers need to design policies and interventions that will ensure equitable enrolment of marginalized ethnic groups.

- The results of this study indicated the presence of adverse selection in the scheme. More detailed studies are recommended to substantiate the occurrence of adverse selection in NHIP and assess the effect it would have upon its financial viability.

Implications for the public

Pre-existing poor health condition of family member and/or being prone to illness have found to influence household's enrolment in National Health Insurance Program (NHIP). This study suggests a need for all households regardless of their illness status to enrol in the scheme in order to ensure better protection against uncertain financial consequences resulting from any impending catastrophic illnesses. Local governments and other community stakeholders also need to play significant roles to raise insurance awareness, engender community trust and increase connectedness of households to government programs and schemes such that all segments of population in their communities are equitably enrolled to the scheme irrespective of ethnicity, economic or morbidity status. 


\section{Background}

In many developing countries, out-of-pocket health expenditure of patients or their families constitute a large proportion of amount spent on healthcare. This proportion has been estimated to be the highest ie, $40.8 \%$ in the World Health Organization (WHO) South East Asia Region. ${ }^{1}$ In Nepal, household out-of-pocket health expenditure alone contributes to $56.3 \%$ of current health expenditure. ${ }^{2}$ In countries where out-of-pocket expenditure is the most important source of healthcare financing, households can experience financial catastrophe and often impoverishment as a result of their out-of-pocket spending on healthcare. ${ }^{1,3}$ Over the past decades, many low- and middle-income countries (LMICs) have faced severe challenges to sustain sufficient financing for healthcare and to provide adequate financial protection against impoverishing effects of catastrophic illness. ${ }^{4}$ Because of these concerns, moving away from out-of-pocket healthcare payments to prepayment social health protection mechanisms has widely been argued as an important step towards reducing risks from financial hardship. A resolution passed by world health assembly in 2005 called for countries to introduce prepayment mechanisms in the health sector for sharing risk as well as to avoid catastrophic healthcare expenditure and impoverishment of individuals as a result of seeking care. ${ }^{5}$ World health report 2010 also advocated health insurance as one of the promising means of subsidizing the entire population and achieving universal healthcare coverage. ${ }^{6}$ Various countries in the world responded to these calls by adopting different health financing mechanisms including voluntary communitybased and social health insurance schemes. ${ }^{7}$

In Nepal, a variety of pre-paid healthcare financing schemes have been launched in the past to strengthen the social health protection of Nepalese citizens. Despite having a long history of private, non-profit health insurance schemes, ${ }^{8,9}$ a government funded community-based health insurance (CBHI) program was initiated in 2003 at 2 districts and was expanded to an additional 4 districts by $2006 .{ }^{10}$ Over the past several years, Ministry of Health made remarkable efforts to expand social health protection through health financing schemes such as Free Basic Healthcare Program, Aama program, Screening and Treatment of Uterine Prolapse and Poverty Stricken Citizens Fund..$^{10}$ Nevertheless several of these schemes experimented in Nepal were often fragmented in resource allocation and inefficient in securing a comprehensive financial protection to its citizens. ${ }^{11,12}$ In this context, Government of Nepal recently embarked on a path to universal coverage through implementation of national social health insurance program. Consequently in 2016, a National Health Insurance Program (NHIP) was introduced in the country beginning its operation at 3 districts (Kailali, Ilam, and Baglung). By the mid of 2017, the program was operational in fifteen districts with gradual expansion to other districts in a phased manner. ${ }^{13}$

Nepal's NHIP is a family-based scheme characterized by voluntary enrolment of households. In many LMICs, voluntary health insurance schemes have often failed to cover a large proportion of their target population. ${ }^{14}$ Even at national level, the government's experience with implementing CBHI schemes in the past did not exhibit positive results. The sustainability of CBHI scheme was threatened by limited coverage of the population. The enrolment in public CBHI schemes ranged from $1.6 \%-12 \%$ of the catchment area population. The enrolment in private CBHI schemes was also lower ie, $2.7 \%$ of the population. ${ }^{10}$ The initial reports of NHIP also highlight difficulties in capturing its target population. Within the first year of its operation, only $5 \%$ of the population was covered by the scheme. ${ }^{13}$ Currently, there have been wider concerns regarding the capacity of NHIP to achieve adequate population coverage and remain viable. Nevertheless, Government of Nepal considers this scheme as a cornerstone for making progress towards universal coverage and aims to expand to all 77 districts by 2020. Given low enrolment in the scheme to date, achieving adequate coverage of households requires understanding factors that influence such enrolment.

Multitudes of factors are shown to have a variable influence on health insurance enrolment, and these factors vary between countries. Large body of literature from various LMICs suggest that enrolment in health insurance program is influenced by range of factors such as age, gender, and education of the household head, household income, household size, presence of children and elderly, place of residence, distance to health facility and household illness experience. ${ }^{14,15}$ However, only a limited number of studies in Asia have explored these factors at household level. ${ }^{16,17}$ Given a unique socio-economic context, health system status and a unique family-based insurance modality of the NHIP, the factors established at those countries are likely to vary in the Nepalese context. Nonetheless, the evidence base for health insurance programs in Nepal remains very weak. It is against this background that the study aimed to identify the factors associated with enrolment of households in the Nepal's NHIP. The evidence generated might inform policy-makers towards addressing the problems of low enrolment in the NHIP.

\section{Overview of Nepal's National Health Insurance Program}

In order to ensure universal coverage, the government of Nepal adopted the National Health Insurance Policy in 2013. The policy aims to ensure equitable and universal access for all Nepalese citizens to necessary quality health services. ${ }^{18}$ Under this policy, a semi-autonomous Social Health Security Development Committee was established in 2015 (after the enactment of Health Insurance Act by the parliament of Nepal in 2017, Social Health Security Development Committee has been replaced by an autonomous Health Insurance Board) and the NHIP was rolled out at Kailali district in April 2016. The program was expanded to the 2 additional districts ie, Baglung and Ilam in June $2016^{19}$ and later the program was gradually expanded in a phase-wise manner to other districts. The government of Nepal aims to expand this program to all 77 districts by $2020 .^{13}$ Premium for NHIP are collected from households and the annual contribution amount depends on the size of the family with Nepali Rupees (NPR) 2500 for families up to 5 members and NPR 425 for each additional member in the family. However, the payment of premium by ultra-poor, poor and marginalized groups are subsidized 
by the government. ${ }^{20}$ There is not any other cost sharing or co-payments with the NHIP, except the premium paid. Each family up to 5 members receives a benefit up to NPR 50000 . Families with more than 5 members receive an additional benefit of NPR 10000 for each additional member of the family not exceeding a maximum benefit ceiling of NRP 100000 per family. ${ }^{13,20}$ The benefit package of the NHIP consists of emergency services, outpatient consultations, inpatient services, selected drugs and diagnostic services. However, some services classified to be unnecessary or very expensive are on the exclusion list. Among these are cosmetic surgery, secondary equipment/machines such as artificial organs, vision glasses (costing more than NPR 500), hearing equipment, services relating to artificial insemination, abortion services, dental services and treatment for injuries resulting from fights or consumption of drugs or alcohol. ${ }^{20}$ NHIP is a cash-less system such that the members can receive services and drugs covered by the program without having to pay at any stage. The provider payments are made by Health Insurance Board on the basis of claims made by providers according to the agreed rates. The claim management process is streamlined through Insurance Management Information System (IMIS). ${ }^{21}$ Table 1 presents key features of the NHIP.

\section{Methods}

Settings for the Study

This study was purposively conducted in Ilam district which was one of the first 3 districts (Kailali, Ilam, and Baglung) that had completed its first year of enrolment cycle. Ilam is a hill district of Eastern Nepal and 1 of the 14 districts of province 1. The district covers an area of $1707 \mathrm{~km}^{2}$ with population of $287916 .{ }^{23}$ It is administratively divided into 6 Palikas (4 municipalities and 6 rural municipalities). Ilam Municipality and Sandakpur rural municipality were selected as study sites. Ilam municipality is district headquarter located at about $600 \mathrm{~km}$ east from Kathmandu, the capital city. Sandakpur rural municipality lies about $20 \mathrm{~km}$ north-east from district headquarter. Both Ilam and Sandakpur have a population of diverse ethnic groups comprising of privileged Brahmins, Chhetris, Gurungs and Newars and underprivileged janajatis (indigenous people) and dalits (the oppressed). ${ }^{24}$ For centuries, these underprivileged groups are socially ascribed lower in the caste/ethnicity hierarchy and face certain disparities in terms of access to healthcare, education, economic opportunities as well as political and social representation. ${ }^{25}$

Study Design and Sampling Procedure

This study was cross-sectional and comparative. 570

Table 1. Key Features of NHIP

\begin{tabular}{|c|c|}
\hline Features & Description \\
\hline Roll out year & - April 2016 \\
\hline Administration & $\begin{array}{l}\text { - Currently administered by an autonomous Health Insurance Board (During the implementation of this study, the scheme was } \\
\text { administered by Social Health Security Development Committee, a semi-autonomous body) } \\
\text { - The board provides membership cards, makes decisions on contribution amounts, develops mechanisms for subsidies to } \\
\text { poor and disadvantaged groups, as well as negotiates with service providers on benefit package, their costs and deals with } \\
\text { provider payments }\end{array}$ \\
\hline Membership & - Voluntary scheme based on family contributions ${ }^{20}$ \\
\hline Sources of revenue & $\begin{array}{l}\text { - Budget allocated by Government of Nepal } \\
\text { - Premium contributions from households where families with up to } 5 \text { members contribute NPR } 2500 \text { (US\$21.59') per year } \\
\text { and NPR } 425 \text { (US\$3.67) per additional member }{ }^{13,20}\end{array}$ \\
\hline Exemptions & - $100 \%$ exemption in annual premium for ultra-poor, $75 \%$ for poor and $50 \%$ for marginalized ${ }^{20}$ \\
\hline $\begin{array}{l}\text { Service delivery } \\
\text { channels }\end{array}$ & $\begin{array}{l}\text { - Public Health Facilities } \\
\text { - Private health facilities selected through contracting }\end{array}$ \\
\hline Benefit Package & $\begin{array}{l}\text { - Benefits of up to NPR } 50000 \text { (US\$431.70) per year are provided to insured families of up to } 5 \text { members with an additional } \\
\text { NPR } 10000 \text { (US\$86.34) covered for each additional member. The maximum amount of benefit available to a family per year } \\
\text { is NPR } 100000^{20} \\
\text { - Covers emergency services, outpatient consultations, selected inpatient services, drugs and diagnostic services } \\
\text { - } \quad \text { Includes } 928 \text { types of medicines }{ }^{13}\end{array}$ \\
\hline Co-payments & - No co-payments or other cost sharing arrangements \\
\hline Exclusion list & $\begin{array}{l}\text { - Services considered to be unnecessary or very expensive are on the exclusion list } \\
\text { - Excludes cosmetic surgery, spectacles costing more than NPR } 500 \text { (US\$4.32), hearing aids, artificial insemination, dental } \\
\text { services and treatment for injuries suffered in a drunken brawl }\left.\right|^{20}\end{array}$ \\
\hline $\begin{array}{l}\text { Provider payment } \\
\text { mechanisms }\end{array}$ & $\begin{array}{l}\text { - Case-based payment for outpatient and emergency services } \\
\text { - Fee for service for inpatient and diagnostic services }\end{array}$ \\
\hline Claim management & $\begin{array}{l}\text { - Service provider health institutions submit claim to Health Insurance Board through IMIS } \\
\text { - } \quad \text { Health Insurance Board reviews and approves the claim for reimbursement to service provider health institutions }\end{array}$ \\
\hline $\begin{array}{l}\text { Information system } \\
\text { used }\end{array}$ & $\begin{array}{l}\text { - Uses an internet-based IMIS. This system is used for registration of membership and renewal, claim management, feedback } \\
\text { and reporting }\end{array}$ \\
\hline
\end{tabular}

Abbreviations: NPR, Nepali Rupees; NHIP, National Health Insurance Program; IMIS, insurance management information system.

a Note: 1 US dollar equivalent to 115.82 NPR based on exchange rate of Nepal Rastra Bank. ${ }^{22}$ 
households were studied by recruiting equal number of enrolled $(n=285)$ and non-enrolled $(n=285)$ households. The sample size was estimated using Epi Info StatCalc software assuming $90 \%$ power of the study and 95\% level of confidence. We assumed the percentage of households from under-privileged group discontinuing the insurance scheme at $56 \%$ with an odds ratio of $1.76 .{ }^{26}$ The sample size for each Palika (municipality) was proportionate to the total number of NHIP enrolled households. The selection of enrolled households at each Palika was done using simple random sampling. The list of enrolled households was obtained from Social Health Security Development Committee (now Health Insurance Board) through its IMIS. Enrolment assistants (volunteers who are responsible to register and enrol families to NHIP) and female community health volunteers helped in locating the sampled households. For every enrolled household recruited for the study, one comparison household (not-enrolled to NHIP) was selected from the nearest neighbour located in any direction. Non-enrolled households living in the study area for less than 6 months were not included in the study.

\section{Data Collection}

A structured questionnaire was developed based on study objectives. A Nepal Demographic and Health Survey questionnaire was adapted for measuring wealth index. ${ }^{27}$ In order to enhance the content validity of the tool, the questionnaire was subjectively assessed by 2 health insurance experts for its content, organization, appropriateness as well as logical flow of the instrument. Contextualization of the tool was done by reviewing national documents on health insurance. The questionnaire was pretested among 44 households before application. The questionnaire included 4 sections; socio-demographic and economic information; morbidity status, perceived health status of the family and enrolment status of households. Household survey to collect data was carried out from September to October 2017. The tool was administered to household heads in Nepali language using face to face interview. A written informed consent was obtained from the participants before interview. One enumerator with a university degree and prior field research experience was trained and mobilized as interviewer.

\section{Variables}

\section{Outcome Variable}

The outcome variable for this study was the health insurance enrolment status of households. Those enrolled in the NHIP were coded as 1 and 0 otherwise.

\section{Explanatory Variables}

The choice of explanatory variables in this study was guided by Anderson and Newman behavioural model of health service utilization ${ }^{28,29}$ and the review of literature on the determinants of enrolment in the health insurance schemes. ${ }^{30-35}$ The behavioural model envisages that household's decision to enrol in health insurance scheme depends on 3 set of factors namely; predisposing factors (demographic, and social structures and health beliefs that predisposes households to enrol in the NHIP), enabling factors (that facilitate or impede households to enrol in the NHIP) and need factors (that induce the need for households to enrol in the NHIP).

In this study, the predisposing factors included age of household head classified into 3 categories (less than 40 years, 40-59 years and 60 years or older); gender of household head (male or female); education of household head (no formal education, up to secondary level education or post-secondary education); household size ( $\leq 5$ members or $>5$ members); family type (nuclear or joint/extended); presence of children aged 0-5 years (no children or at least one children); presence of elderly above 60 years (no elderly or at least one elderly); number of family members who had completed their secondary education (none or at least one member) and ethnicity (privileged or underprivileged). Privileged ethnic group comprised of upper caste people (Brahmin and Chhetri) and relatively advantaged janajatis (Newar and Gurung) and underprivileged ethnic group comprised of dalits and disadvantaged janajatis. The socio-economic status of households was examined as a predisposing factor. This was measured by constructing a wealth index using principal component analysis based on data on household ownership of durable assets. The components included were ownership of house, electronic assets (television, refrigerator, computer/ laptop), mobile and non-mobile telephone, vehicles, animals, types of fuel used for cooking and source of drinking water. These components were converted into a weighted index (factor score) and the households were then divided into 5 quintiles of wealth. ${ }^{36}$ The first quintile represented the poorest segment of the population and fifth quintile, the least poor. Needs factors in this study included morbidity conditions of households and perceived health status of the family. Morbidity conditions of households was assessed using 2 variables; past illness experience and presence of chronic illness in the family. Past illness experience was a self-reported response in which respondents were asked to recall if any of their family members had experienced any acute illness requiring health facility visit within 3 months preceding the survey. The responses were recorded as "Yes" or "No." The presence of chronic illness was recorded as "Yes" if at least one of members in family suffered from either of heart disease, diabetes, chronic obstructive pulmonary disease, and cancer. Perceived health status of family was rated as good, average, or poor. Table 2 presents a summary of the study variables.

\section{Data Management and Analysis}

A digital questionnaire was prepared using Epi Info application and data were collected using tablets. To prevent the risk of data loss, the collected data was uploaded to cloud storage on a daily basis. Compilation of data was done in Epi Info ${ }^{\mathrm{TM}}$ 7.2.1.0 and then exported to IBM SPSS Statistics version 23.0 for cleaning and analysis. Descriptive statistics were used to report the demographic and socio-economic factors, morbidity characteristics and perception. The wealth index was generated using principal component analysis. Pearson's chi-square test was performed to test the association of independent variable with enrolment in NHIP. Multiple logistic regression was used to investigate the effect of these 
Table 2. Summary of Study Variables

\begin{tabular}{|c|c|c|}
\hline Variable & Definition of Variables & Measurements \\
\hline \multicolumn{3}{|c|}{ Outcome Variable } \\
\hline Enrolment status & Status of the household's membership in the NHIP & Enrolled (coded 1), not-enrolled (coded 0) \\
\hline \multicolumn{3}{|c|}{ Explanatory Variables } \\
\hline Age & $\begin{array}{l}\text { Age of household in completed years at the time of } \\
\text { household survey }\end{array}$ & Less than 40 years, $40-59$ years, 60 years or older \\
\hline Gender & Gender of household head & Male, female \\
\hline Education & $\begin{array}{l}\text { The highest level of education attained by household } \\
\text { head }\end{array}$ & $\begin{array}{l}\text { No formal education, up to secondary level, post- } \\
\text { secondary education }\end{array}$ \\
\hline Ethnicity & Ethnicity of household members & $\begin{array}{l}\text { Privileged (upper caste people and advantaged janajati), } \\
\text { under-privileged (dalits and disadvantaged janajati) }\end{array}$ \\
\hline Household size & $\begin{array}{l}\text { The number of family members living in the } \\
\text { household }\end{array}$ & Five or less members, more than 5 members \\
\hline Family type & Type and composition of family & Nuclear, joint or extended \\
\hline Presence of children aged $0-5$ years & $\begin{array}{l}\text { The number of children aged between } 0 \text { to } 5 \text { years } \\
\text { present in the household }\end{array}$ & None, at least 1 child \\
\hline Presence of elderly above 60 year & $\begin{array}{l}\text { The number of elderly members above } 60 \text { years } \\
\text { present in the household }\end{array}$ & None, at least 1 elderly \\
\hline $\begin{array}{l}\text { No. of members completed } \\
\text { secondary education }\end{array}$ & $\begin{array}{l}\text { The number of family members who have completed } \\
\text { their secondary education }\end{array}$ & None, at least 1 member \\
\hline Socio-economic status & $\begin{array}{l}\text { Socio-economic position of households based on } \\
\text { wealth quintile }\end{array}$ & Richest, rich, middle, poor, poorest \\
\hline Illness experience & $\begin{array}{l}\text { Number of family members who experienced any } \\
\text { acute illness within } 3 \text { months prior to the survey } \\
\text { period }\end{array}$ & None, at least 1 member \\
\hline Presence of chronic illness & $\begin{array}{l}\text { Number of family members who have at least one } \\
\text { chronic illness }\end{array}$ & None, at least 1 member \\
\hline $\begin{array}{l}\text { Perceived health status of the } \\
\text { family }\end{array}$ & $\begin{array}{l}\text { Health status of the family as rated by the household } \\
\text { head }\end{array}$ & Good, average, poor \\
\hline
\end{tabular}

Abbreviation: NHIP, National Health Insurance Program.

variables on the odds of enrolment in the NHIP. Multicollinearity of variables was tested before entering them in the regression analysis. No problem of collinearity was seen among the variables (the highest observed VIF was 1.937). All variables significant at $15 \%$ significance level in bivariate analyses were considered for multiple logistic regression. ${ }^{38}$ The goodness of fit of regression model was tested by the application of Hosmer and Lemeshow chi-square test; the model was found to be a good fit $(P>.05)$.

The regression model was explained by the equation:

$\log [\mathrm{Y} /(1-\mathrm{Y})]=b_{\mathrm{o}}+b_{1} X_{1}+b_{2} X_{2}+b_{3} X_{3} \ldots . . b_{\mathrm{n}} X_{\mathrm{n}}+\mathrm{e}$

Where $Y$ is the expected probability for the outcome variable to occur, $b_{\mathrm{o}}$ is the constant/intercept, $b_{1}$ through $b_{\mathrm{n}}$ are the regression coefficients and the $X_{1}$ through $X_{\mathrm{n}}$ are distinct independent variables and $\mathrm{e}$ is the error term.

\section{Results}

Characteristics of the Study Population

The mean age of respondents was 41.8 (standard deviation $[\mathrm{SD}]=13.5$ years). Majority (87.4\%) of the households were headed by males. While more than one in 3 household heads (35.3\%) had completed their secondary level education, nearly 1 in 5 household heads (18.6\%) had no formal education. The average household size of the study population was 4.8 (SD $=1.6)$.
More than half of the surveyed households belonged to privileged ethnic group (56.1\%). Majority households had equal to or less than 5 members (74.4\%) and lived in a nuclear family (54.7\%). Slightly less than one-third households (30.2\%) had children below 5 years of age and about 2 in 5 households (39.6\%) had elderly members above 60 years of age. Three in 4 households (76.3\%) had at least 1 family member who had completed their secondary education. Two in 5 households (43.5\%) had at least 1 family member with illness experience in past 3 months. More than one-third households (36.1\%) had a family member suffering from chronic illness. Slightly more than one in ten household heads (13.5\%) perceived health status of their family as poor (Table 3 ).

\section{Factors Associated With Enrolment in NHIP}

In the bivariate analyses of enrolment in NHIP with demographic and socio-economic factors, morbidity characteristics and perception, significant association was found with education of household head $(P=.001)$, household size $(P=.035)$, type of family $(P<.001)$, ethnicity $(P<.001)$, presence of elderly $(P=.001)$, number of members with completed secondary education $(P<.001)$, socioeconomic status $(P<.001)$, illness experience in family $(P<.001)$, and presence of chronic illness $(P<.001)$. Gender of household head, presence of children and perceived health status of family did not show any significant association with enrolment of households in NHIP (Table 4). 
Table 3. General Characteristics of the Study Population $(n=570)$

\begin{tabular}{|c|c|c|c|}
\hline Characteristics & Number & Percent & $95 \% \mathrm{Cl}$ \\
\hline \multicolumn{4}{|l|}{$\mathrm{Age}^{\mathrm{a}}$} \\
\hline Less than 40 years & 275 & 48.2 & $44.1-52.4$ \\
\hline $40-59$ years & 224 & 39.3 & $35.3-43.4$ \\
\hline 60 years or older & 71 & 12.5 & $9.9-15.5$ \\
\hline \multicolumn{4}{|l|}{ Gender } \\
\hline Male & 498 & 87.4 & $84.4-90.0$ \\
\hline Female & 72 & 12.6 & $10.0-15.6$ \\
\hline \multicolumn{4}{|l|}{ Education of household head } \\
\hline No formal education & 106 & 18.6 & $15.5-22.0$ \\
\hline Up to secondary level (grade 1-10) & 263 & 46.1 & $42.0-50.3$ \\
\hline Post-secondary education (>grade 10) & 201 & 35.3 & $31.3-39.3$ \\
\hline \multicolumn{4}{|l|}{ Ethnicity } \\
\hline Privileged ethnic group & 320 & 56.1 & $52.0-60.3$ \\
\hline Underprivileged ethnic group & 250 & 43.9 & $39.7-48.0$ \\
\hline \multicolumn{4}{|l|}{ Household size $^{b}$} \\
\hline Five or less members & 424 & 74.4 & 70.6-77.9 \\
\hline More than 5 members & 146 & 25.6 & $22.1-29.4$ \\
\hline \multicolumn{4}{|l|}{ Family type } \\
\hline Nuclear & 312 & 54.7 & $50.5-58.9$ \\
\hline Joint or extended & 258 & 45.3 & $41.1-49.5$ \\
\hline \multicolumn{4}{|l|}{ Presence of children aged $0-5$ years } \\
\hline None & 398 & 69.8 & $65.9-73.6$ \\
\hline At least 1 child & 172 & 30.2 & $26.4-34.1$ \\
\hline \multicolumn{4}{|l|}{ Presence of elderly above 60 years } \\
\hline None & 344 & 60.4 & $56.2-64.4$ \\
\hline At least one elderly & 226 & 39.6 & $35.6-43.8$ \\
\hline \multicolumn{4}{|l|}{ Illness experience (in past 3 months) } \\
\hline None & 322 & 56.5 & $52.3-60.6$ \\
\hline At least one member & 248 & 43.5 & $39.4-47.7$ \\
\hline \multicolumn{4}{|l|}{ Presence of chronic illness } \\
\hline None & 364 & 63.9 & $59.8-67.8$ \\
\hline At least one member & 206 & 36.1 & $32.2-40.2$ \\
\hline \multicolumn{4}{|l|}{ Perceived health status of family } \\
\hline Good & 275 & 48.2 & $44.1-52.4$ \\
\hline Average & 218 & 38.2 & $34.2-42.4$ \\
\hline Poor & 77 & 13.5 & $10.8-16.6$ \\
\hline
\end{tabular}

${ }^{\text {a }}$ Mean \pm standard deviation $[S D]=41.8 \pm 13.5$.

${ }^{\mathrm{b}}$ Mean $\pm \mathrm{SD}=4.8 \pm 1.6$.

During the regression analysis, enrolment in NHIP showed significant association with ethnicity, socio-economic status, illness experience in family and presence of chronic illness. The odds that households would enrol in NHIP were higher among those with higher socio-economic status. Richest households were 4 times more likely to enrol in NHIP (adjusted odds ratio [AOR]: 4.08, 95\% CI: 2.15-7.72) compared to those in a poorest category. Similarly, households belonging to the privileged ethnic group were 1.7 times more likely (AOR: 1.71, 95\% CI: 1.18-2.48) to enrol in NHIP compared to ones from underprivileged ethnic group. The households in which at least one of their members experienced acute illness were 1.5 times more likely (AOR: 1.51, 95\% CI: 1.04-2.19) to enrol in NHIP compared to households that did not have such illness experience. Similarly, households with chronically ill members were 1.8 times more likely (AOR: 1.84, 95\% CI: 1.23-2.73) to enrol in NHIP compared to households that did not suffer a chronic illness (Table 5).

\section{Discussion}

Our study results showed that belonging to privileged ethnic group, having a higher socio-economic status, having an experience of acute illness by family member and presence of chronic illness in the family are the potential factors that influence the enrolment of households in NHIP.

This study confirmed an association between ethnicity and household enrolment in the NHIP. The households from privileged ethnic groups were more likely to enrol in NHIP compared to those from underprivileged ethnic groups. This might be explained by the fact that underprivileged ethnic groups are more likely to be financially unstable and have relatively less access to information and services. Hill janajati and hill dalits represent significantly higher proportions of the poor in Nepal..$^{39}$ Paying for enrolment into the social security schemes like NHIP might therefore be too difficult for these groups. Previous studies have also confirmed the role of ethnicity in determining the enrolment of households in the health insurance schemes. ${ }^{32,40,41}$ Evidences from studies in various LMICs have shown a positive association between wealth or socio-economic status and health insurance uptake..$^{34,35,42,43}$ Bivariate and multivariate analyses in this study also confirmed a similar association. The richest households were 4 times more likely to enrol in NHIP as compared to those in poorest category. One explanation for these findings might be that richer and ethnically privileged families are better connected to the government and enrol more in other non-healthcare related government programs and services. With greater interactions, they might have better exposure to insurance information and knowledge on how to enrol. In a study about United States Medicaid program, Saavedra showed that those enrolled in other forms of government programs are more likely to have health insurance coverage. ${ }^{44}$

Despite the policy provisions to subsidize the premium of the poor and marginalized, ${ }^{20}$ NHIP does not seem to provide financial protection to these segments of population. The study results clearly show marked differences in enrolment status between rich-poor and privileged-underprivileged ethnic groups. These findings point out the issues of inequity in enrolment. This might be because the pro-poor targeting have not yet been realized in practice due to the delay in distribution of poverty identification cards to these segments of the population..$^{13}$ Addressing these disparities in enrolment of household in the NHIP across socio-economic and ethnic group is necessary to accelerate the pace towards achieving universal health coverage.

This study found an association between experience of acute illness and enrolment in the NHIP. The presence of chronically ill member in the household also showed significant association with NHIP enrolment. Similar 
Table 4. Association of Enrolment in NHIP With Various Characteristics

\begin{tabular}{|c|c|c|c|c|c|}
\hline \multirow{2}{*}{$\begin{array}{l}\text { Demographic, Socio-economic, Morbidity } \\
\text { Characteristics and Perception }\end{array}$} & \multicolumn{2}{|c|}{ Enrolled $(n=285)$} & \multicolumn{2}{|c|}{ Not-enrolled ( $n=285$ ) } & \multirow{2}{*}{$P$ Value } \\
\hline & No. (\%) & $95 \% \mathrm{Cl}$ & No. (\%) & $95 \% \mathrm{Cl}$ & \\
\hline Gender of household head & & & & & .313 \\
\hline Male & $253(50.8)$ & $46.3-55.3$ & $245(49.2)$ & $44.7-53.7$ & \\
\hline Female & $32(44.4)$ & $32.7-56.6$ & $40(55.6)$ & $43.4-67.3$ & \\
\hline Education of household head & & & & & $.001^{\mathrm{a}}$ \\
\hline Secondary level and higher & $120(59.7)$ & $52.6-66.5$ & $81(40.3)$ & $33.5-47.4$ & \\
\hline Below secondary level & $165(44.7)$ & $39.6-49.9$ & $204(55.3)$ & $50.1-60.4$ & \\
\hline Household size & & & & & $.035^{\mathrm{a}}$ \\
\hline More than 5 members & $84(57.5)$ & 49.1-65.7 & $62(42.5)$ & $34.3-50.9$ & \\
\hline Five or less members & $201(47.4)$ & $42.6-52.3$ & $223(52.6)$ & $47.7-57.4$ & \\
\hline Family type & & & & & $<.001^{\mathrm{a}}$ \\
\hline Joint/Extended & $150(58.1)$ & $51.9-64.2$ & $108(41.9)$ & $35.8-48.1$ & \\
\hline Nuclear & $135(43.3)$ & $37.7-49.0$ & $177(56.7)$ & $51.0-62.3$ & \\
\hline Ethnicity & & & & & $<.001^{\mathrm{a}}$ \\
\hline Privileged ethnic group & $191(59.7)$ & $54.1-65.1$ & $129(40.3)$ & $34.9-45.9$ & \\
\hline Underprivileged ethnic group & $94(37.6)$ & $31.6-43.9$ & $156(62.4)$ & $56.1-68.4$ & \\
\hline Presence of children aged $0-5$ years & & & & & .584 \\
\hline At least 1 & $83(48.3)$ & $40.6-56.0$ & $89(51.7)$ & $44.0-59.4$ & \\
\hline None & $202(50.8)$ & $45.7-55.8$ & $196(49.2)$ & $44.2-54.3$ & \\
\hline Presence of elderly above 60 years & & & & & $<.001^{\mathrm{a}}$ \\
\hline At least 1 & $132(58.4)$ & $51.7-64.9$ & $94(41.6)$ & $35.1-48.3$ & \\
\hline None & $153(44.5)$ & 39.1-49.9 & $191(55.5)$ & $50.1-60.9$ & \\
\hline No. of members completed secondary education & & & & & $<.001^{\mathrm{a}}$ \\
\hline At least 1 & $236(54.3)$ & $49.4-59.0$ & $199(45.7)$ & $41.0-50.6$ & \\
\hline None & $49(36.3)$ & $28.2-45.0$ & $86(63.7)$ & $55.0-71.8$ & \\
\hline Socio-economic status & & & & & $<.001^{\mathrm{a}}$ \\
\hline Q1-Poorest & $39(34.2)$ & $25.6-43.7$ & $75(65.8)$ & $56.3-74.4$ & \\
\hline Q2-Poor & $61(41.5)$ & $33.4-49.9$ & $86(58.5)$ & $50.1-66.6$ & \\
\hline Q3-Middle & $32(41.5)$ & $31.8-55.3$ & $42(56.8)$ & $44.7-68.2$ & \\
\hline Q4-Rich & $62(52.5)$ & $43.1-61.8$ & $56(47.5)$ & $38.2-56.9$ & \\
\hline Q5-Richest & $91(77.8)$ & $69.2-84.9$ & $26(22.2)$ & $15.1-30.8$ & \\
\hline Illness experience (in past 3 months) & & & & & $<.001^{\mathrm{a}}$ \\
\hline At least 1 member & $149(60.1)$ & $53.7-66.2$ & $99(39.9)$ & $33.8-46.3$ & \\
\hline None & $136(42.2)$ & $36.8-47.8$ & $186(57.8)$ & $52.2-63.2$ & \\
\hline Number of members with chronic illness & & & & & $<.001^{\mathrm{a}}$ \\
\hline At least 1 member & $134(65.0)$ & $58.1-71.5$ & $72(35.0)$ & $28.5-41.9$ & \\
\hline None & $151(41.5)$ & $36.4-46.7$ & $213(58.5)$ & $53.3-63.6$ & \\
\hline Perceived health status of family & & & & & .214 \\
\hline Good & $144(52.4)$ & $46.3-58.4$ & $131(47.6)$ & $41.6-53.7$ & \\
\hline Average & $99(45.4)$ & $38.7-52.3$ & $119(54.6)$ & $47.7-61.3$ & \\
\hline Poor & $42(54.5)$ & $42.8-65.9$ & $35(45.5)$ & $34.1-57.2$ & \\
\hline
\end{tabular}

Abbreviation: NHIP, National Health Insurance Program.

a Statistically significant at $P<.05$.

findings have also been reported in several studies from other LMICs. ${ }^{17,45,46}$ These findings support the notion that families with pre-existing health conditions or more prone to being ill have a greater tendency to enrol in a health insurance scheme. From a public health perspective, this is very encouraging as it enhances healthcare access for those with poor health. ${ }^{17,47}$ The observed association also indicates the possibility of adverse selection taking place in a NHIP which is critical from a sustainability point of view. Adverse selection results when high-risk or sick individuals enrol more in the health insurance schemes compared to low-risk or healthy individuals. Adverse selection might limit potential for cross-subsidies and can affect the sustainability and financial viability of the scheme. ${ }^{17,48}$

In the case of Nepal's NHIP, entire households are enrolled as unit. Household enrolment is ideally believed to lessen the problems of adverse selection by bringing into the insurance pool all healthier family members those who would not otherwise enrol. ${ }^{49}$ Nevertheless, the financial viability of the scheme can be threatened if the provisions for household 
Table 5. Odds of Enrolment in NHIP Due to Various Characteristics

\begin{tabular}{|c|c|c|}
\hline \multirow{2}{*}{$\begin{array}{l}\text { Demographic, Socio-economic and } \\
\text { Morbidity Characteristics }\end{array}$} & \multicolumn{2}{|c|}{ Enrolment in NHIP } \\
\hline & OR & $95 \% \mathrm{Cl}$ \\
\hline \multicolumn{3}{|l|}{ Education of household head } \\
\hline Secondary level and higher & 1.37 & $0.90-2.07$ \\
\hline Below Secondary level & 1 & 1 \\
\hline \multicolumn{3}{|l|}{ Household Size } \\
\hline More than 5 & 0.97 & $0.58-1.62$ \\
\hline Less than or equal to 5 & 1 & 1 \\
\hline \multicolumn{3}{|l|}{ Family type } \\
\hline Joint/extended & 1.41 & $0.86-2.31$ \\
\hline Nuclear & - & 1 \\
\hline \multicolumn{3}{|l|}{ Ethnicity } \\
\hline Privileged group & $1.71^{\mathrm{a}}$ & $1.18-2.48$ \\
\hline Underprivileged group & 1 & 1 \\
\hline \multicolumn{3}{|l|}{ No. of elderly above 60 years } \\
\hline At least 1 & 1.11 & $0.71-1.74$ \\
\hline None & 1 & 1 \\
\hline \multicolumn{3}{|c|}{ No. of members completed secondary education } \\
\hline At least 1 & 1.18 & $0.73-1.92$ \\
\hline None & 1 & 1 \\
\hline \multicolumn{3}{|l|}{ Socio-economic status } \\
\hline Richest & $4.08^{\mathrm{a}}$ & 2.15-7.72 \\
\hline Rich & 1.53 & $0.86-2.75$ \\
\hline Middle & 1.27 & $0.67-2.40$ \\
\hline Poor & 1.08 & $0.63-1.86$ \\
\hline Poorest & 1 & 1 \\
\hline \multicolumn{3}{|l|}{ Illness experience (in last 3 months) } \\
\hline At least 1 member ill & $1.51^{\mathrm{a}}$ & $1.04-2.19$ \\
\hline None & 1 & 1 \\
\hline \multicolumn{3}{|l|}{ Presence of chronic illness } \\
\hline At least 1 member chronically ill & $1.84^{\mathrm{a}}$ & $1.23-2.73$ \\
\hline None & - & 1 \\
\hline
\end{tabular}

Abbreviations: OR, odds ratio; NHIP, National Health Insurance Program. a Statistically significant at $P<.05$.

enrolment are not strictly enforced. In a study of rural mutual healthcare health insurance scheme in China, Wang et al found significant adverse selection among partially enrolled households because the policy to enrol households as a unit was not fully enforced. ${ }^{50}$ Similar situation in Nepal's NHIP therefore cannot be ruled out where there are also possibilities for larger size households to partially enrol their sickest member. Since the partial enrolment status of households was not examined by our study, we recommend detailed studies to substantiate the presence of adverse selection and to assess whether it would threaten the financial viability of the scheme.

Considering the patriarchal nature of Nepalese society, men are conventionally considered responsible for major financial decisions within the households. In contrast to this presumption, gender of household head in this study showed no association with enrolment in NHIP. The available evidence however is mixed regarding association between gender of household head and enrolment in health insurance scheme. While some studies suggested that female headed households are more likely to purchase health insurance, ${ }^{31,34,40}$ others have shown that male headed households are more likely to enrol in health insurance program, ${ }^{35,51}$ and yet other studies reported no significant association in enrolment in health insurance schemes between male and female headed households. ${ }^{32,52}$

Although factor such as education of household head was significantly associated in bivariate analysis, this relationship was not significant after adjustments using regression analysis. However, the role of education of household head in enrolling their families into health insurance schemes cannot be ruled out. Studies from Bangladesh, Ghana, Burkina Faso, and Zimbabwe have shown positive associations between health insurance uptake and higher education of household head. $32,33,35,46,53$ Also our study did not find any significant association between poor perceived health status and increased uptake of health insurance although other studies have established such association. ${ }^{34,54}$

The findings of this study might be relevant to policy and decision-makers interested in increasing the NHIP enrolment rates for households. First, the policy-makers should consider the fact that poor socio-economic households are less enrolled to NHIP than households with higher socio-economic status. Simply proclaiming subsidies for poor and marginalized households may not be enough to induce these households to enrol into the NHIP. Robust and timely measures might be necessary in order to put the pro-poor targeting policy into practice. Second, policy-makers may wish to ensure that households from underprivileged ethnic groups have as much access to health insurance program as families from privileged ethnic groups. Health Insurance Board and policy-makers need to design policies and interventions that will ensure equitable enrolment of unreached marginalized ethnic groups. At the meantime, local governments and other community stakeholders could play a significant role to raise insurance awareness, engender community trust and increase the connectedness of households to government programs and schemes.

To the best of our knowledge, this study provides an early evidence on the factors associated with household enrolment in the newly implemented health insurance program of Nepal. Although the findings of this study are consistent with large body of literatures from various LMICs, we could not relate these findings to our national context owing to the limited number of literatures available for Nepal. The results of this study might be affected by the purposive selection of the study sites. Furthermore, the selection of neighbours of enrolled households for comparison might have introduced a selection bias. Due to the cross-sectional nature of our data, it was not possible to demonstrate a temporal relationship between enrolment in NHIP and explanatory variables. Despite these limitations, the results of the study will add to the knowledge base on the NHIP and generally be useful to policy- and decision-makers at the government and health insurance board and those in academia.

\section{Conclusion}

Belonging to the privileged ethnic group, having a higher socio-economic status, experiencing an acute illness and 
presence of chronically ill member in the family are the factors associated with enrolment of households in NHIP. Our study revealed gaps in enrolment between rich-poor households and privileged-underprivileged ethnic groups. Despite the stated pro-poor targeting of the NHIP, there is a clear gap between the policy and its practice. Extending health insurance coverage to poor and marginalized households is therefore needed to increase equity and accelerate the pace towards achieving universal health coverage.

\section{Acknowledgements}

This study was funded by the University Grants Commission under it Masters Research Support Program to the first author (Award no. MRS/74_75/HS-6). Department of Community Medicine and Public Health, Maharajgunj Medical Campus provided an institutional support to complete this study. The authors also acknowledge the support of Health Insurance Board. We thank Keshab Sanjel and Narayan Budhathoki for their editorial assistance. We are grateful to the study participants, field enumerator who contributed to data collection and enrolment assistants and female community health volunteers who helped in locating the sampled households.

\section{Ethical issues}

The research protocol was approved by Institutional Review Board at Institute of Medicine, Tribhuwan University, Kathmandu, Nepal.

\section{Competing interests}

Authors declare that they have no competing interests.

\section{Authors' contributions}

PG designed the study, acquired data, performed data analysis and drafted the manuscript. Both VPS and AKP participated in the conception and design of the study and provided important critical revisions of the manuscript for important intellectual content. AKP provided critical inputs during statistical analysis. All authors read and approved the final manuscript.

\section{References}

1. WHO. World health statistics 2016: monitoring health for the SDGs sustainable development goals: Geneva: World Health Organization; 2016.

2. Pandey J, Karna R, Shrestha D, Neupane G, Bajracharya B. Nepal national health accounts, 2009/2010-2011/2012. Kathmandu, Nepal: Ministry of Health, Government of Nepal; 2016.

3. Saito E, Gilmour S, Rahman MM, Gautam GS, Shrestha PK, Shibuya K. Catastrophic household expenditure on health in Nepal: a cross-sectional survey. Bull World Health Organ. 2014;92(10):760767. doi:10.2471/BLT.13.126615

4. Gottret P, Schieber G. Health financing revisited: a practitioner's guide. The World Bank; 2006.

5. WHO. Sustainable health financing, universal coverage and social health insurance, Resolution WHA58.33. Geneva: World Health Organization; 2005.

6. WHO. The world health report 2010: health systems financing: the path to universal coverage. Geneva: World Health Organization; 2010.

7. Giedion U, Andrés Alfonso E, Díaz Y. The impact of universal coverage schemes in the developing world: a review of the existing evidence. 2013.

8. Ghimire R. Community based health insurance practices in Nepal. International Research and Reviews. 2013;2(4).

9. An inventory of micro-insurance schemes in Nepal. Kathmandu: International Labour Office in Nepal, International Labour Organization; 2003.

10. Stoermer M, Fuerst F, Rijal K, et al. Review of community-based health insurance initiatives in Nepal. Deutsche Gesellschaft fur internationale Zusammenarbeit (GIZ) Gmbh; 2012.

11. Pokharel R, Silwal PR. Social health insurance in Nepal: A health system departure toward the universal health coverage. Int J Health Plann Manage. 2018. doi:10.1002/hpm.2530

12. Torres LV, Gautam GS, Fuerst F. Assessment of the government health financing system in Nepal: suggestions for reform. Deutsche Gesellschaft für Internationale Zusammenarbeit; 2011.

13. Annual Report for FY 2073/74. Kathmandu: Social Health Security Development Committee; 2017.

14. Acharya A, Vellakkal S, Taylor $F$, et al. Impact of national health insurance for the poor and the informal sector in low- and middleincome countries. London: The EPPI-Centre; 2012.

15. Dror DM, Hossain SS, Majumdar A, Koehlmoos TLP, John D, Panda PK. What factors affect voluntary uptake of communitybased health insurance schemes in low- and middle-income countries? a systematic review and meta-analysis. PLoS One. 2016;11(8):e0160479. doi:10.1093/heapol/czh014

16. Kamath R, Sanah N, Machado LM, Sekaran VC. Determinants of enrolment and experiences of Rashtriya Swasthya Bima Yojana (RSBY) beneficiaries in Udupi district, India. Int J Med Public Health. 2014;4(1). doi:10.4103/2230-8598.127164

17. Alkenbrack S, Jacobs B, Lindelow M. Achieving universal health coverage through voluntary insurance: what can we learn from the experience of Lao PDR? BMC Health Serv Res. 2013;13(1):521. doi:10.1186/1472-6963-13-521

18. Government of Nepal. National health insurance policy. Kathmandu: Ministry of Health and Population; 2013.

19. Ministry of Health. Annual Report for 2015/2016. Kathmandu: Department of Health Services; 2017.

20. Social health security program operation rules (second amendment). Kathmandu: Social Health Security Deveopment Committee; 2017.

21. Government of Nepal. Social health security programme: Standard operating procedures. Kathmandu: Social Health Security Development Committee; 2016.

22. Foreign exchange rates. https://www.nrb.org.np/fxmexchangerate. php. Accessed September, 2018.

23. Brief introduction of rural municipality and municipality. Kathmandu: Ministry of Federal Affairs and Local Development; 2017.

24. National population and housing census 2011 (National report). Kathmandu, Nepal: National Planning Commission Secretariat, Central Bureau of Statistics; 2012.

25. Bennet L, Dahal D, Govindasamy P. Caste, ethnic and regional identity in Nepal: further analysis of the 2006 Demographic and Health Surveys. Calverton, Maryland, USA: Macro International Inc; 2008.

26. Mainali D. Community based health insurance practices in Mangalbare primary health care centre, Morang district [Thesis]. Kathmandu: Tribhuwan University, Institute of Medicine; 2011.

27. MOHP. Nepal demographic and health survey 2011. Kathmandu, Nepal: Ministry of Health and Population, New ERA, and ICF International; 2012.

28. Andersen R, Newman JF. Societal and individual determinants of medical care utilization in the United States. Milbank Q. 2005;83(4). doi:10.1111/j.1468-0009.2005.00428.x

29. Andersen RM. Revisiting the behavioral model and access to medical care: does it matter? J Health Soc Behav. 1995;36(1):1-10. doi: $10.2307 / 2137284$

30. Aregbeshola BS, Khan SM. Predictors of enrolment in the National Health Insurance Scheme among women of reproductive age in Nigeria. Int J Health Policy Manag. 2018;7(11):1015. doi:10.15171/ ijhpm.2018.68

31. Jehu-Appiah C, Aryeetey G, Spaan E, de Hoop T, Agyepong I, Baltussen R. Equity aspects of the National Health Insurance Scheme in Ghana: who is enrolling, who is not and why? Soc Sci Med. 2011;72(2):157-165. doi:10.1016/j.socscimed.2010.10.025

32. De Allegri $M$, Kouyaté $B$, Becher $\mathrm{H}$, et al. Understanding enrolment in community health insurance in sub-Saharan Africa: a populationbased case-control study in rural Burkina Faso. Bull World Health Organ. 2006;84(11):852-858.

33. Manortey S, Alder S, Crookston B, Dickerson T, VanDerslice J, 
Benson S. Social deterministic factors to participation in the National Health Insurance Scheme in the context of rural Ghanaian setting. $J$ Public Health Afr. 2014;5(1). doi:10.4081/jphia.2014.352

34. Kusi A, Enemark U, Hansen KS, Asante FA. Refusal to enrol in Ghana's National Health Insurance Scheme: is affordability the problem? Int $J$ Equity Health. 2015;14(1):2. doi:10.1186/s12939014-0130-2

35. Alatinga KA, Williams JJ. Towards universal health coverage: exploring the determinants of household enrolment into National Health Insurance in the Kassena Nankana District, Ghana. Ghana Journal of Development Studies. 2015;12(1-2):88-105. doi:10.4314/ gjds.v12i1-2.6

36. Vyas S, Kumaranayake L. Constructing socio-economic status indices: how to use principal components analysis. Health Policy Plan. 2006;21(6):459-468. doi:10.1093/heapol/czl029

37. Filmer D, Pritchett LH. Estimating wealth effects without expenditure data-or tears: an application to educational enrollments in states of India. Demography. 2001;38(1):115-132. doi:10.1353/ dem. 2001.0003

38. Bursac Z, Gauss CH, Williams DK, Hosmer DW. Purposeful selection of variables in logistic regression. Source Code Biol Med. 2008;3(1):17. doi:10.1186/1751-0473-3-17

39. Poverty in Nepal 2010-11. Kathmandu: Central Bureau of Statistics; 2011.

40. Adhikari N, Wagle RR, Adhikari DR, Thapa P, Adhikari M. Factors affecting enrolment in the community based health insurance scheme of Chandranigahapur hospital of Rautahat district. J Nepal Health Res Counc. 2018;16(41):378-384. doi:10.33314/jnhrc.1581

41. Badu E, Agyei-Baffour P, Ofori Acheampong I, Preprah Opoku $\mathrm{M}$, Addai-Donkor K. Households sociodemographic profile as predictors of health insurance uptake and service utilization: a cross-sectional study in a municipality of Ghana. Adv Public Health. 2018;2018. doi:10.1155/2018/7814206

42. Chankova S, Sulzbach S, Diop F. Impact of mutual health organizations: evidence from West Africa. Health Policy Plan. 2008;23(4):264-276. doi:10.1093/heapol/czn011

43. Vellakkal S. Determinants of enrolment in voluntary health insurance: evidences from a mixed method study, Kerala, India. International Journal of Financial Research. 2013;4(2). doi:10.5430/ijfr.v4n2p99

44. Saavedra M. Children's health insurance, family income, and welfare enrollment. Child Youth Serv Rev. 2017;73:182-186. doi:10.1016/j. childyouth.2016.12.014

45. Aggarwal A. Achieving equity in health through community-based health insurance: India's experience with a large CBHI programme. J Dev Stud. 2011;47(11):1657-1676. doi:10.1080/00220388.2011.6 09586

46. Mhere F. Health insurance determinants in Zimbabwe: case of Gweru urban. J Appl Bus Econ. 2013;14(2):62.

47. Parmar D, Souares A, De Allegri M, Savadogo G, Sauerborn R. Adverse selection in a community-based health insurance scheme in rural Africa: implications for introducing targeted subsidies. BMC Health Serv Res. 2012;12(1):181. doi:10.1186/1472-6963-12-181

48. McIntyre D. Learning from experience: Health care financing in low-and middle-income countries. Geneva: Global forum for health research Geneva; 2007.

49. Rajkotia Y, Frick K. Does household enrolment reduce adverse selection in a voluntary health insurance system? Evidence from the Ghanaian National Health Insurance System. Health Policy Plan. 2012;27(5):429-437. doi:10.1093/heapol/czr057

50. Wang H, Zhang L, Yip W, Hsiao W. Adverse selection in a voluntary Rural Mutual Health Care health insurance scheme in China. Soc Sci Med. 2006;63(5):1236-1245. doi:10.1016/j.socscimed.2006.03.008

51. Dong H, Kouyate B, Cairns J, Sauerborn R. Differential willingness of household heads to pay community-based health insurance premia for themselves and other household members. Health Policy Plan. 2004;19(2):120-126. doi:10.1093/heapol/czh014

52. Kapologwe NA, Kagaruki GB, Kalolo A, et al. Barriers and facilitators to enrollment and re-enrollment into the community health funds/ Tiba Kwa Kadi (CHF/TIKA) in Tanzania: a cross-sectional inquiry on the effects of socio-demographic factors and social marketing strategies. BMC Health Serv Res. 2017;17(1):308. doi:10.1186/ s12913-017-2250-z

53. Iqbal M, Chowdhury AH, Mahmood SS, Mia MN, Hanifi S, Bhuiya A. Socioeconomic and programmatic determinants of renewal of membership in a voluntary micro health insurance scheme: evidence from Chakaria, Bangladesh. Glob Health Action. 2017;10(1):1287398. doi:10.1080/16549716.2017.1287398

54. Boateng D, Awunyor-Vitor D. Health insurance in Ghana: evaluation of policy holders' perceptions and factors influencing policy renewal in the Volta region. Int $J$ Equity Health. 2013;12(1):50. doi:10.1186/1475-9276-12-50 